\title{
REFLEXIÓN: ¿SUJETO U OBJETO? ¿CÓMO CONSIDERAR A LA MADRE O ADULTO SIGNIFICATIVO EN CONTEXTOS DE INTERVENCIÓN SOCIAL EN ABUSO SEXUAL INFANTIL, DESDE EL TRABAJO SOCIAL?
}

\section{REFLECTION: SUBJECT OR OBJECT? HOW TO CONSIDER THE MOTHER OR SIGNIFICANT ADULT IN CONTEXTS OF SOCIAL INTERVENTION IN CHILD SEXUAL ABUSE, FROM SOCIAL WORK?}

Fecha recepción: agosto de 2019 / fecha aceptación: noviembre de 2019

Luis Alberto Donoso Estay ${ }^{1}$

Cómo citar este artículo:

Donoso, L., (2019) Reflexión: ¿'Sujeto u objeto? ¿Cómo considerar a la madre o adulto significativo en contextos de intervención social en abuso sexual infantil, desde trabajo social? Revista Pensamiento y Acción Interdisciplinaria, 5(2), 55-63. DOI: http://doi.org/10.29035/pai.5.2.55

\section{Resumen}

El presente documento intenta responder a una interrogante que surge desde el ejercicio profesional y la posterior reflexión del Trabajo Social realizado durante algunos años y que tiene relación con el cómo se considera en el contexto de la intervención social familiar a la madre o adulto responsable de un niño, niña o joven víctima de abuso sexual; como sujeto u objeto. Esta pregunta, adquiere mayor sentido al considerar la influencia que ha tenido el positivismo dominante en este tipo de intervenciones, separando al sujeto del objeto, lo cual repercute en el trabajo a realizar, donde el/ la profesional trabajador/a social muchas veces se transforma en el/la protagonista, desconociendo o no considerando percepciones, significados, interpretaciones $\mathrm{u}$ otros aspectos relevantes de la progenitora o figura significativa en un contexto marcado por el sufrimiento y el dolor.

Palabras Claves: Sujeto, Objeto, Abuso Sexual Infantil, Intervención Social, Trabajador/a Social.

1 Asistente Social, chileno. Licenciado en Trabajo Social Universidad Católica del Maule, Magister en Trabajo Social Pontificia Universidad Católica de Valparaíso, Chile. Correo electrónico: luisalbertodonoso@gmail.com 


\begin{abstract}
This document attempts to answer a question that arises from the professional exercise of Social Work carried out for some years and that is related to how the mother or adult responsible for a child or young victim of sexual abuse is considered in the context of family social intervention; as subject or object. This question acquires more sense when considering the influence that dominant positivism has had in this type of interventions, separating the subject from the object, which has an impact on the work to be done, where the social worker professional often transforms in the protagonist, ignoring or not considering perceptions, meanings, interpretations or other relevant aspects of the parent or significant figure in a context marked by suffering and pain.
\end{abstract}

Keywords: Subject, Object, Child Sexual Abuse, Social Intervention, Social Worker.

\title{
Introducción
}

La experiencia, aprendizaje, ideas, prácticas y la reflexión de la acción profesional del Trabajo Social desarrollado hace un tiempo con familias en la que alguno de sus integrantes ha sido víctima de Abuso Sexual Infantil (ASI), ha permitido el desarrollo del presente documento.

Desde esta disciplina, en este tipo de intervenciones, la resignificación social es uno de los pilares de la acción profesional desarrollada, ya que se busca generar procesos de construcción de argumentos que permitan potenciar socialmente la vida de las personas, en este caso la del niño, niña o joven víctima y el adulto que acompaña, específicamente la madre, ya que es ella generalmente la figura más cercana en la vida del/la infante o del/la joven, por lo tanto se transforma en un actor clave en el trabajo a realizar, ya que el apoyo materno es uno de los elementos más significativos en la búsqueda de la moderación del impacto de la experiencia abusiva. Por lo tanto, reflexionar cómo es considerada la progenitora en las intervenciones desarrolladas desde el Trabajo Social en esta temática, es determinante y más que necesario para potenciar el trabajo que se realiza, considerando que la resignificación social "se construye creyendo en que siempre se puede lograr algo mejor en la vida cotidiana, para así seguir la lucha incesante para diseñar presentes y futuros mejores para la gente, para acompañarla profesionalmente en los recorridos más oscuros de la sociedad, para iluminarlos y que con esa luminosidad se puedan diagnosticar vacíos, debilidades, pérdidas, pero también rehacer procesos, descubrir fortalezas y fortalecer potencialidades". (Evangelista, 2018, p.21) 


\section{Marco referencial}

Cuando se está inmerso profesionalmente en este tipo de problemática, donde el abuso sexual infantil es el común denominador, es posible observar y constatar desde la práctica, algunas de las siguientes situaciones a nivel de intervención:

1. Disfuncionalidades que cronifican los abusos hasta llegar a naturalizarlos muchas veces. Estas disfuncionalidades, se traducen en dificultades en los patrones de apego de los padres o del adulto significativo.

2. Situaciones de violencia intrafamiliar física y psicológica, donde muchas veces quien agrede físicamente es quien también violenta sexualmente.

3. Familias que presentan escasa vinculación con redes sociales, que permite que las situaciones de victimización sexual se perpetúen en el tiempo, imposibilitando la develación y con ello que alguien detenga las agresiones.

4. Familias que presentan un alto índice de socialización patriarcal, que marca fuertemente las dinámicas y relaciones entre los integrantes, principalmente hacia la figura de la mujer, que en su rol de madre, queda en una posición de subordinación, que se acrecienta cuando presentan historias de vida marcadas por situaciones de malos tratos, cuidados negligentes e incluso experiencias de abuso sexual mientras era niña o adolescente, generando problemas de autoestima, al sentirse disminuidas en sus capacidades, con falta de autonomía, de autodeterminación, pero que aun así, debe continuar con su rol de cuidadora, ya que socialmente se le presiona desde una configuración patriarcal como la principal responsable de cuidar y proteger a los hijos. De ahí entonces que, al momento de ocurrir situaciones de abuso sexual, predomine una visión culpabilizadora y sancionadora hacia ella, silenciando el dolor que pueda sentir al momento de enfrentarse a una situación extremadamente difícil como es la victimización sexual, no solo cuando debe hacer frente, sino también cuando debe elaborar lo ocurrido, resultando ser muchas veces traumático, dificultando constituirse como figuras protectoras para los hijos en algunas oportunidades.

Afortunadamente, esto no es una generalidad, ya que también pueden conformarse como figuras de importancia ante la develación o ante la denuncia de las agresiones.

De ahí entonces, la importancia de realizar procesos de intervención con ellas, porque a pesar de lo grave que pueda ser la situación, o lo mal que se puedan sentir, muchas veces son el eje central del sistema familiar, por lo tanto, el empoderarlas, permite reorientar el funcionamiento familiar, y otorgar protección, y con ello ofrecer a la víctima, niño, niña o joven (en adelante NNJ) la reinserción a una familia que sea capaz de sostener un proceso de intervención. 
En consecuencia, las intervenciones sociales en situaciones de abuso sexual infantil con tales características, son sin duda un gran desafío para los/las profesionales del Trabajo Social, considerando que los hechos abusivos ocurridos al interior de las familias, producen verdaderos nudos relacionales, que quedan estancados en el tiempo, que no permiten que el adulto significativo sea capaz de visualizar, ni mucho menos generar un discurso que señale aquellos patrones relacionales que crean, y mantienen ocultas situaciones abusivas, debiendo convivir con las situaciones de victimización sexual permanentemente y buscar la sobrevivencia.

Acceder al mundo simbólico y subjetivo del sujeto social, puede ayudar a encontrar respuestas a esta especie de laberinto sin salida y potenciar el trabajo a realizar con la madre o adulto significativo. Sin embargo, para realizar una intervención con esta mirada, es necesario revisar y reflexionar desde qué perspectiva está actuando el/la trabajador/a social para conocer la realidad social en la que debe intervenir; cómo conoce el mundo del otro, es decir,, cómo se relaciona con su objeto de intervención, en este caso la madre de un NNJ víctima de abuso sexual desde la relación sujeto-objeto, considerando que "no hay objeto si no es con respecto a un sujeto (que observa, que aísla, define, piensa), y no hay sujeto si no es con respecto a un ambiente objetivo (que le permite reconocerse, definirse, pensarse, etc., pero también existir" (Morín, 2001, p.67), por lo tanto, es fundamental realizar una introspección al respecto, considerando la influencia que para el Trabajo Social de Caso, que es lo más cercano a este tipo de intervención, ha tenido el positivismo cartesiano y las posteriores corrientes epistemológicas surgidas a mediados del siglo XX.

Para esta revisión, es necesario entonces hacer hincapié en la cibernética de segundo orden, específicamente su visión sistémica, las perspectivas criticas-dialécticas, el humanismo y el lenguaje, por su impacto en el Trabajo Social.

Al adentrarse en cada una de estas corrientes por separado, es posible plantear desde la visión sistémica, que la realidad es concebida circularmente, permitiendo conocer una realidad en su totalidad, desde las causas que mantienen una determinada situación, desechando una lectura desde una perspectiva lineal que da énfasis en prestar atención a los síntomas. Por consiguiente, este enfoque sistémico invita a observar una parte del todo, donde el profesional que diagnóstica un problema, lo hace desde una posición determinada, por esta razón, existen múltiples maneras de interpretar e intervenir una situación, dependiendo desde donde se sitúa el profesional.

La lectura desde esta circularidad permite comprender que un sistema no solo responde a estímulos que puedan provenir desde fuera, sino también a estímulos que se producen en el propio sistema, de esta manera, la relación sujeto-objeto, está en constante fusión, puesto que, quien interviene cuenta con saberes teóricos y metodológicos, y aquel que es intervenido, también posee saberes, al contar con información valiosa en relación al problema que se busca 
intervenir, ya que es él, quien vive la dificultad, generando una relación recíproca que incluye al observador en su observación, es decir, un individuo trabajando con otro individuo.

Por otra parte, la perspectiva crítica-dialéctica, señala que no existe una separación entre sujeto-objeto, ya que quien observa una situación particular también es parte de la cultura de aquello que observa, o sea sus ideas, percepciones, están condicionadas por la cultura. Esta situación permite comprender la relación entre sujeto-objeto con una mayor profundidad y no solo categorizar los hechos sociales.

Desde una óptica humanista, se plantea que los individuos son autónomos e independientes que buscan permanentemente desarrollarse; entonces en esta perspectiva se busca generar una relación con el otro fundada desde la ayuda, es decir, en un encuentro profundo que genere un proceso de soporte, de aprendizaje mutuo y significativo, potenciando una relación entre sujetos, y no de sujeto-objeto. De esta manera, quien recibe ayuda se transforma en protagonista de su proceso de crecimiento.

Finalmente, el lenguaje, comprendido como una entidad compleja y no solo como una forma de acceder a la realidad, es capaz de imponer límites, puede por ejemplo construir y reformular la realidad, de tal modo que, para poder comprenderla, es necesario recurrir al lenguaje, ya que, a través de él, el sujeto puede acceder a ella y posteriormente presentarla a los demás, modificando sustancialmente la relación sujeto-objeto (realidad).

Todas estas concepciones señaladas, han sido capaces de demostrar que la relación sujeto-objeto, no necesariamente pueden concebirse solo desde el positivismo cartesiano, sino también desde una mirada integradora, donde sujetoobjeto no están separados. Cabe preguntarse entonces, ¿Qué repercusiones tiene situarse desde una vereda distinta en la intervención profesional, que se realiza con la madre de un NNJ víctima de ASI?, pues una fundamental: rompe lo convencional, permitiendo comprender a la figura adulta como un sujeto pensante y no como un objeto pasivo y mero receptor, sino más bien un sujeto con capacidades y habilidades, es decir, un sujeto social, que puede mirarse asimismo críticamente, siendo consciente que todo pensamiento en sí mismo, le permite alcanzar una mayor sabiduría, construir una mente abierta, capaz de reflexionar y con ello levantar dudas frente a lo dogmático, a aquello que se encuentra naturalizado o asumido como una verdad inmodificable, por lo tanto, es capaz de determinarse, informarse, opinar y movilizarse para intentar afrontar la situación que padece, reconstruyendo significados, y con ello, no solo modificar los discursos frente al abuso sexual, sino también las prácticas, ya que como se señalaba anteriormente, el rol que juega la progenitora u otro adulto significativo ante la ausencia de ésta, es central para realizar una intervención social, al permitir sostener un proceso de trabajo con miras a resignificar la situación abusiva. 


\section{Conclusiones}

Parece entonces, que es posible y necesario acceder a los pensamientos, asunciones, expectativas y creencias que las madres poseen en torno al ASI, y así no homogeneizar la intervención, y aceptar la multidimensionalidad de la realidad, dejando de lado la mirada del experto, que determina cuál es el problema y decide qué hacer, permitiendo el encuentro con un sujeto que piensa, que posee una historia, y que está construyendo otra desde su presente, para decidir aquello que más le acomoda y las metas que desea alcanzar dentro de la intervención a desarrollar, en un contexto histórico, económico, social, político, cultural, institucional e incluso ético, específico, todos factores que juegan un papel importante en la relación que establece el/la trabajador/a social y la madre de un NNJ víctima de agresión sexual, porque esta multiplicidad de factores los influencia a ambos, por lo tanto la definición de sujeto, no solo tiene relación con la participación protagónica de una madre, sino también con la realidad que los afecta, ya que a los dos los condiciona; además de sus historias personales, sus formaciones valóricas e incluso la institución que los cobija, siendo todos elementos, que en su conjunto generan una realidad compleja, única e irrepetible.

En consecuencia, la presencia y existencia de un sujeto, permite crear una alternativa distinta a los métodos tradicionales de intervención de tipo positivista, ya que posibilita una mirada más comprensiva, frente a situaciones de ASI, facilitando la construcción de relaciones horizontales, de diálogo, que promuevan el intercambio de conocimientos e ideas, para así generar reflexión frente a lo ocurrido.

En palabras de Evangelista (2018) desarrollar "un proceso educativo, político y metodológico orientado a la toma de decisiones y al desarrollo de acciones que permiten dar capacidad de respuesta, tanto emergente, coyuntural o estratégica, a una serie de necesidades, problemas, intereses y demandas", (p.20) facilita rescatar de los sujetos sociales, sus propios conocimientos, recursos, herramientas, experiencias, procesar información, acumular fuerzas, tomar decisiones, desarrollar acciones con convicción, con confianza, para influir en su entorno familiar positivamente, mejorarlo y así transformarlo y con ello ser protagonistas en su propio contexto de cambio, con un/a trabajador/a social, dispuesto/a a ser acompañante, promotor/a y facilitador/a, en una realidad que comparte con este sujeto social, buscando potenciar la interacción, capacidades y destrezas para construir una relación dialógica y así generar un espacio de encuentro necesario para una participación consciente.

Entonces, no se debe olvidar, que "el trabajador social es en esencia un profesional-acompañante que facilita procesos educativos entre los sujetos con los que se relaciona dialógicamente, con la finalidad de que los mismos desarrollen ampliamente sus potencialidades colectivas en la auto-construcción de sus problemáticas y necesidades sociales sentidas y estratégicas". (Evangelista, 2018, p.129).

Esta reflexión, toma mayor importancia para el/la trabajador/a social que se desempeña en esta temática de violencia, considerando los contextos muchas 
veces tensionados en los que este tipo de intervenciones se desarrollan, porque los sujetos sociales con quienes trabaja se caracterizan por presentar una serie de dificultades anexas al ASI o derivadas de este, que se suceden simultáneamente y que suelen generar incertidumbre, malestar, pesimismo y agobio y porque además el profesional, generalmente debe actuar bajo las orientaciones y marcos institucionales en los que está inserto, los cuales muchas veces son rígidos e instrumentales, generando una posición incómoda, con escaso tiempo para el desarrollo de las intervenciones, falta de recursos para llevar a cabo un trabajo efectivo y eficiente; todos hechos que impiden construir y ejecutar intervenciones sociales centradas en el otro y desde el otro, cayendo en el juego de edificar una intervención social comprendida como una acción unilateral, en la que el profesional que interviene determina, delimita y aprueba acciones a desarrollar, sin considerar la opinión de los individuos con quienes se trabaja, construyendo una relación paternalista, vertical y en ocasiones autocrática.

En resumen, el realizar una intervención social fundada en otros parámetros; el que el/la profesional tenga claro conocimiento desde cual o cuales de las perspectivas epistemológicas descritas anteriormente se está actuando en la práctica, permite advertir la adherencia al positivismo ciegamente, al punto de transformarlo "en sinónimo de proceder científico: reducir lo objetivo a lo fáctico, poner fuera todo el campo de la intencionalidad-básico al analizar lo social- y dejar el plano valórico entregado en palabras de Habermas, un dogmatismo que separa razón y decisión"(Matus, 2002, p.42).

No se trata de realizar procesos de intervención desde el sentido común y rechazar a la ciencia, sino de tener presente que la lectura positivista de la ciencia se ha vuelto en ocasiones ideológica, olvidando muchas veces que existen formas diferentes de desarrollar procesos de intervención con el otro, más aún en un una relación profesional cara a cara que busca diagnosticar, proponer, evaluar y por sobretodo acompañar a un sujeto que busca apoyo, atención y contención, por lo tanto, conocer las particularidades del otro, analizar su contexto, y desde ahí desarrollar estrategias procedimentales, a través de un entendimiento mutuo y colaborativo entre sujeto-trabajador/a social, es un camino coherente y necesario, que invita a salir del autoconcepto del "experto", y transitar hacia una mayor apertura cognitiva, pensando en que el conocimiento que se trae muchas veces es incompleto y que se necesita la mirada del otro, para realizar un proceso de intervención social más efectivo y eficaz y por sobretodo que haga sentido al sujeto social.

Para finalizar, es necesario recordar, que el mundo no es el espacio físico en el que se habita, aquel que posiblemente se ve todos los días, que se analiza como quien observa una silla, un auto, una casa o cualquier cosa o materialidad que está allá afuera, sino que es el espacio en el que necesariamente se transita, es el lugar desde donde se entiende lo cotidiano, transformándose en una representación propia del mundo, ya que, de otra forma no se podría conocer y entender como tal, por lo tanto es necesario mirar más allá; desde el otro y con el otro. 


\section{Referencias bibliográficas}

Aylwin, N. y Solar, M. (2003). Trabajo Social Familiar. Santiago: Salesianos.

Bárcena, F. (2006). El Aprendizaje del Dolor. Notas para una Simbólica del Sufrimiento Humano. Madrid: Universidad Complutense de Madrid.

Barudi, J. y Dantagnan, M. (2009). Los Buenos Tratos a la Infancia. Barcelona: Gedisa.

Berger, P. y Luckmann, T. (2003). La Construcción Social de la Realidad. Buenos Aires: Amorrortu.

De Robertis, C. (2006). Metodología de la Intervención en Trabajo Social. Buenos Aires: Lumen.

Descartes, R. (2009). Discurso del Método. Buenos Aires: Ediciones Colihue.

Echeverría, R. (2012). El Búho de Minerva. Introducción a la Filosofía Moderna. Santiago: JC Sáez.

Evangelista, E. (2018). Aproximaciones al Trabajo Social Contemporáneo. Ciudad de México: Editorial Entorno Social.

Giddens, A. (1990). The Consequences of Modernity. California: Stanford University.

Habermas, J. (1987). Teoría de la Acción Comunicativa. Vol II. Madrid: Taurus.

Kisnerman, N. (1998). Pensar el Trabajo Social. Una Introducción desde el Construccionismo. Buenos Aires: Lumen Hvmanitas.

Martuccelli, D. (2007). Cambio de Rumbo. La sociedad a Escala del Individuo. Santiago: LOM.

Maturana, H. y Varela, F. (1973). De Máquinas y Seres Vivos: Una Teoría sobre la Organización Biológica. Santiago: Editorial Universitaria.

Matus, T. (2002). Propuestas Contemporáneas en Trabajo Social. Hacia una Intervención Social Polifónica. Buenos Aires: Espacio.

Morin, E. (2012). Introducción al Pensamiento Complejo. Barcelona: Gedisa. 
Pensamiento y Acción Interdisciplinaria, Volumen 5, número 2, año 2019. ISSN 0719-8078. pp. 55-63

Dirección de correspondencia:

Luis Donoso

Asistente Social, Licenciado en Trabajo Social Universidad Católica del Maule, Magister en Trabajo Social Pontificia Universidad Católica de Valparaíso, Chile.

\section{Contacto:}

luisalbertodonoso@gmail.com

\footnotetext{
(C) $\$$ (2) Esta obra se encuentra bajo una Licencia de Creative Commons
}

BY NC SA Reconocimiento-NoComercial-Compartirlgual 4.0 Internacional 